\title{
Oral administration of Fumagillin DCH protects chinook salmon Oncorhynchus tshawytscha from experimentally-induced proliferative kidney disease
}

\author{
R. P. Hedrick*, J. M. Groff, P. Foley, T. McDowell \\ Aquaculture and Fisheries Program, Department of Medicine, School of Veterinary Medicine, University of California, Davis, \\ California 95616, USA
}

\begin{abstract}
The antibiotic Fumagillin DCH was found to be effective in controlling experimental infections with PKX, the myxosporean that causes proliferative kidney disease (PKD) in salmonid fish. Following 6 or 7 wk of treatment, experimentally infected chinook salmon Oncorhynchus tshawytscha showed no evidence of PKX cells, or of the renal inflammation characteristic of PKD, on withdrawal of the treatment and for up to 7 wk afterwards. In contrast, 90 to $100 \%$ of fish (in 2 experiments) that were injected with PKX, but not given the antibiotic, had numerous PKX cells in the kidney and developed clinical PKD. This is the first report of an effective orally administered drug for the control of a myxozoan infection in salmonid fish.
\end{abstract}

\section{INTRODUCTION}

Proliferative kidney disease (PKD) is considered to be one of the most serious diseases of farm-reared trout in Europe and also causes major losses among Pacific salmon in North America (Clifton-Hadley et al. 1984, Hedrick et al. 1984). The severe inflammation of the kidney that characterizes the disease is caused by PKX, the vegetative stage of a poorly understood myxozoan (Kent \& Hedrick 1986). Although the precise taxonomic position of PKX has not been determined, recent observations by Hedrick et al. (1988) suggest that it is a myxosporean and that PKX cells are most likely the trophozoites of a Sphaerospora $\mathrm{sp}$.

Although myxosporean diseases of fish are generally considered not to be treatable, recent reports have shown that some chemical prophylaxis is possible. Alderman (1986) showed that although orally administered Proguanil and Clamoxyquin did not prevent whirling disease, they reduced the pathology in rainbow trout Salmo gairdneri induced by the responsible myxosporean Myxobolus (Myxosoma) cerebralis and inhibited spore formation by the parasite. In addition,

- Addressee for correspondence
Clifton-Hadley \& Alderman (1987) found that periodic bath treatments with malachite green effectively reduced the severity and prevalence of PKD in rainbow trout. In the study, malachite green was found to be concentrated in certain tissues of the rainbow trout and this in combination with the teratogenic and carcinogenic potential of the dye have precluded its use with food fish (Meyer \& Jorgensen 1983).

The antibiotic Fumagillin DCH $(2,4,6,8$-Decatetraenedioic acid mono-15-methoxy-4-\{2-methyl-3-(3-methyl-2-butenyl)oxiranyl $\}$-1-oxaspirol $\{2.5\}$ ox-6-yl $\}$ ester $)$ is effective in controlling microsporidian diseases such as that caused by Nosema apis in honey bees Apis mellifica (Katznelson \& Jamieson 1952, Bailey 1953) and that caused by Perezia pyraustae in the corn borer Ostrinia nubilalis (Lynch \& Lewis 1971). Kano et al. (1982) also showed the potential of the drug for treating Pleistophora infections in eels Anguilla japonica. Molnár et al. (1987) have recently demonstrated the potential of using Fumagillin against the myxosporean Sphaerospora renicola in common carp Cyprinus carpio. They found that a medicated diet $11 \mathrm{~g}$ Fumagillin DCH per $\mathrm{kg}$ of feed) was effective in controlling renal sphaerosporosis caused by $S$. renicola in common carp. Feeding Fumagillin prior to or during natural or experi- 
mental exposures to the parasite either prevented the disease altogether or greatly reduced its severity. The morphological (and presumably taxonomic) similarities between developmental stages of the parasites causing renal sphaerosporosis in carp and PKD in salmonids (Kent \& Hedrick 1986) prompted us to test Fumagillin DCF as a potential drug against PKX infections in chinook salmon.

\section{MATERIALS AND METHODS}

Fish. Chinook salmon Oncorhynchus tshawytscha were obtained from the Iron Gate Hatchery (California Department of Fish and Game, Kalamath, California, USA) as yolk sac fry. They were reared in the laboratory on $16^{\circ} \mathrm{C}$ well water for 4 mo. The mean weights of the fish at the start of Expts 1 and 2 were 5.5 and $9.4 \mathrm{~g}$, respectively.

Experimental infections. Chinook salmon were divided into 2 groups of 70 fish each. One group of fish received intraperitoneal (i.p.) injections of $0.1 \mathrm{ml}$ of a homogenate made by placing 2 kidneys from chinook salmon with PKD into $10 \mathrm{ml}$ of minimal essential medium (MEM) (Kent \& Hedrick 1985). This inoculum contained approximately $10^{4} \mathrm{PKX}$ cells, a dose found to induce clinical infections in test fish (Kent \& Hedrick 1985). Fish in the control group received $0.1 \mathrm{ml}$ of MEM. Fish in both experimental and control groups were then divided equally ( 35 per group) between two $20 \mathrm{l}$ aquaria receiving $16^{\circ} \mathrm{C}$ well water at a flow rate of approximately $0.81 \mathrm{~min}^{-1}$. One group of the experimentally infected fish and one control group received medicated diet while the duplicate groups received normal diet. In the second experiment the same procedure was followed except that the number of fish was reduced from 70 to 50 in the initial groups, each of which was divided and held in two 201 aquaria (25 fish per aquarium).

Medicated diets. Fumagillin DCH obtained from the Chinoin Pharmaceutical and Chemical Works Ltd (Budapest, Hungary) was mixed with cod liver oil and applied to a prepared dry diet at a concentration of $1.0 \mathrm{~g}$ (Expt 1) or $0.5 \mathrm{~g}$ (Expt 2) of drug per $\mathrm{kg}$ of diet. A control diet containing cod liver oil but no fumagillin was also prepared. The control and experimental diets were stored at $-20^{\circ} \mathrm{C}$ and fed daily at ca $1 \%$ body weight per day.

In Expt 1, fish were fed medicated diet beginning the day after the injections; this was continued for 7 wk after which time all groups received control diets (no drug) until the experiment was terminated at $14 \mathrm{wk}$. In Expt 2, control diet was fed for $7 \mathrm{~d}$ following the injections; following this, medicated diet was fed to one group of fish inoculated with PKX and to another injected with MEM until the conclusion of the study Due to the smaller number of fish in Expt 2, all fish were sacrificed at $7 \mathrm{wk}$, a period sufficient for the development of the initial stages of the parasite.

Detection and severity of PKD. The presence of the PKX myxosporean and the severity of PKD in the chinook salmon receiving experimental and control diets was determined by sacrificing fish at selected intervals. The degree of renal swelling was observed and graded on an arbitrary scale of - to +++ (no swelling to severe hypertrophy with folded capsule). A portion of the kidney was preserved in Davidson's fixative and later processed by standard histological techniques (Humason 1979). Sections stained with hematoxylin and eosin were then examined for the presence of PKX. In Expt 1, 10 fish were removed from each group at 7,10 , and $14 \mathrm{wk}$ following injection. In Expt 2, all fish were examined at $7 \mathrm{wk}$ post-injection.

\section{RESULTS}

\section{Experiment 1}

Chinook salmon receiving Fumagillin in the diet (1.0 $\mathrm{g} \mathrm{kg}^{-1}$ diet) were completely protected from the development of PKD (Table 1). No renal swelling or PKX cells were detected in any of the PKX-challenged fish receiving the medicated diet. In contrast, chinook salmon injected with PKX and fed the control diet exhibited renal swelling and contained numerous parasites at each of the 3 sampling dates (Table 1). There was no evidence of PKD in any of the control chinook salmon that were injected with MEM.

In Expt 1, both groups of fish receiving medicated

Table 1 Oncorhynchus tshawytscha. Effect of Fumagillin $\mathrm{DCH}$ on the PKX myxosporean, the causative agent of proliferative kidney disease in chinook salmon (Expt 1). Fumagillin DCH was mixed with fish oil and then sprayed onto a dry diet for a final concentration of $1 \mathrm{~g} \mathrm{~kg}^{-1}$ diet and fed for 7 wk. For the remainder of the study all fish received control diet with no drug. Fish were fed once daily at a rate approximately equal to $1 \%$ of their body weight. Ten fish were sacrificed at selected times following experimental infection with the parasite and examined for renal swelling and for the presence of PKX cells

\begin{tabular}{|lccc|}
\hline Treatment & \multicolumn{4}{c|}{ Fish with PKX } \\
& \multicolumn{2}{c|}{ (degree of renal swelling) } \\
& $7 \mathrm{wk}$ & $10 \mathrm{wk}$ & $14 \mathrm{wk}$ \\
& & & \\
\hline PKX + Fumagillin & $0(-)$ & $0(-)$ & $0(-)$ \\
PKX & $90(++)$ & $100(+++)$ & $50(++)$ \\
Control + Fumagillin & $0(-)$ & $0(-)$ & $0(-)$ \\
Control & $0(-)$ & $0(-)$ & $0(-)$ \\
\hline
\end{tabular}


diets began to show inappetence at $6 \mathrm{wk}$ post-injection. This was suspected to be due to toxic effects of the drug. After $7 \mathrm{wk}$ of medication, the medicated groups were switched to the control diet for the remainder of the experiment. An examination of the fish at $14 \mathrm{wk}$ post-injection ( 7 wk following withdrawal of medicated diet), indicated that neither PKD nor parasites developed in the group originally infected with PKX. In contrast, $50 \%$ of the group receiving PKX cells by injection and fed control diet throughout the experiment still showed some renal swelling and parasites at 14 wk (Table 1).

Histological sections of kidney samples from the control and experimental groups were also examined for pathological changes. Chinook salmon receiving drug (i.e. those injected with PKX or with MEM) showed same depletion of the hematopoietic cells in the kidney interstitium and vacuolation of the epithelium of the renal tubules. These changes were not observed in unmedicated fish. Thickening of the glomerular membranes was seen in all groups of fish but it was more pronounced among fish receiving Fumagillin.

\section{Experiment 2}

Chinook salmon fed a diet containing $0.5 \mathrm{~g}$ of Fumagillin $\mathrm{kg}^{-1}$ feed were also protected from experimental infections with the PKX parasite (Table 2). This experiment differed from the first in that feeding of medicated diet was not initiated immediately; instead, medication was started $1 \mathrm{wk}$ following i.p. injections of parasites into the experimental group. In addition, the drug was fed continuously for 6 instead of $7 \mathrm{wk}$ and the fish were all sacrificed and examined for the presence of renal swelling and PKX.

Table 2. Oncorhynchus tshawytscha. Effect of Fumagillin $\mathrm{DCH}$ on the PKX myxosporean, the causative agent of proliferative kidney disease in chinook salmon (Expt 2). Fumagillin DCH was mixed with fish oil and then sprayed onto a dry diet for a final concentration of $0.5 \mathrm{~g} \mathrm{~kg}^{-1}$ diet and fed beginning 1 wk following inoculation with PKX for the duration of the study. Fish were fed once daily at a rate approximately equal to $1 \%$ of their body weight. All fish (25 per group) were sacrificed at $7 \mathrm{wk}$ following experimental infection and examined for renal swelling and for the presence of PKX cells

\begin{tabular}{|cc|}
\hline Treatment & $\begin{array}{c}\text { Fish with PKX } \\
\text { (degree of renal swelling) } \\
7 \mathrm{wk}\end{array}$ \\
\hline $\mathrm{PKX}+$ Fumagillin & $0(-)$ \\
$\mathrm{PKX}$ & $90(++)$ \\
Control + Fumagillin & $0(-)$ \\
Control & $0(-)$ \\
\hline
\end{tabular}

At this concentration of antibiotic in the feed, there were no indications of inappetence, and the fish fed vigorously throughout the $6 \mathrm{wk}$ period of medication. No pathological changes were evident in kidney sections prepared from the medicated chinook salmon; sections from these fish were indistinguishable from those of the uninfected controls receiving non-medicated diet.

\section{DISCUSSION}

In both experiments, Fumagillin $\mathrm{DCH}$ added to the diet was found to effectively prevent the development of PKX and the renal swelling accompanying infection with this myxosporean. The antibiotic was effective at concentrations in the feed as low as $0.5 \mathrm{~g} \mathrm{~kg}^{-1}$ when fish were fed at approximately $1 \%$ body weight per day. These findings were similar to those reported by Molnár et al. (1987) who reported that Fumagillin fed at $1 \mathrm{~g} \mathrm{~kg}^{-1}$ feed prevented renal sphaerosporosis in common carp. In their study, feeding of the drug prior to infection or immediately after experimental injections of the K-protozoans (early developmental stages of Sphaerospore renicola) was found to be required to ensure the efficacy of Fumagillin. In contrast, we found Fumagillin to be effective even when it was first administered $1 \mathrm{wk}$ following i.p. injections of chinook salmon with PKX (Expt 2).

The experiments reported here demonstrate that Fumagillin effectively eradicates PKX when the parasites are administered in a single dose. The means by which Fumagillin kills the parasite is not known but in microsporidian infections it is believed to preferentially affect DNA or RNA synthesis of the parasite (Hartwig \& Przelecka 1971, Jaronski 1972). Liu (1973) saw ultrastructural changes in the microsporidian Nosema apis that suggested that the antibiotic was affecting spore membranes. Direct action on the multiplication and viability of the microsporidian Encephalitozoon cuniculi was demonstrated in vitro by Shadduck (1980) although the mechanism of action of the drug was not determined.

One difficulty experienced in nearly all trials with Fumagillin has been the recurrence of the target parasites (various amebae) following cessation of treatment (Killough et al. 1952, Lynch \& Lewis 1971). This, and the availability of better amebicidal drugs, were the reasons that human trials were discontinued.

Under the conditions of our study with PKD, there was no evidence for the recurrence of the causative parasite following withdrawal of the drug. As shown in Expt 1, there was no evidence of any developmental stages of the parasite or of pathological changes in chinook salmon from the group that was infected with PKX, fed the medicated diet for $7 \mathrm{wk}$, then observed for 
$7 \mathrm{wk}$ following the cessation of medication. These data clearly showed that the antibiotic can control the parasite when administered early in the infection. However, further work is required to better define the dosages that are effective against the parasite but non-toxic to the host.

Preliminary trials with rainbow trout Salmo gairdneri have indicated that levels of 0.5 to $1.0 \mathrm{~g}$ of drug $\mathrm{kg}^{-1}$ diet fed at $1.5 \%$ of body weight for $8 \mathrm{wk}$ can cause mortality at the high dose and depletion of the hematopoietic tissues at both doses (unpubl.). Fish at the highest dose lost their appetite after $8 \mathrm{wk}$ of treatment and showed severe hypertrophy in the spleen and the anterior kidney. Microscopic changes in the hematopoietic tissues, similar to those found among chiñook salmon in Expi 1 , diso occurred.

In the 2 previously reported studies with Fumagillin in fish, there was no mention of any toxic changes. However, in neither study were tissues examined histologically (Kano et al. 1982, Molnár et al. 1987). We have found that toxicity in rainbow trout can be substantially reduced by using dosages of 0.13 to $0.25 \mathrm{~g}$ $\mathrm{kg}^{-1}$ diet and feeding at $1.0 \%$ fish body weight per day. Current studies are also examining the efficacy of Fumagillin at these dosages in protecting rainbow trout from continuous exposures to the infectious stage of the parasite. We are interested in this because it has been demonstrated that the infectious stage is present for at least $7 \mathrm{mo}$ of the year at one trout culture site in California (Foott \& Hedrick 1987).

Our tests with chinook salmon show Fumagillin to be a potent anti-PKD drug. However, further data are needed on its efficacy under field conditions, its effects on growth rates and on the tissue residues that occur. The drug might be used prophylactically during periods of high infectivity to prevent the serious losses associated with the disease in rainbow trout in Europe and chinook salmon in the USA. Fumagillin is well suited for treatments in chinook salmon because the disease strikes only during the short freshwater rearing period (often only 2 to $4 \mathrm{mo}$ ) before the fish are released for their seaward migrations. Adults returning 3 to 5 yr later would presumably have had an ample withdrawal time from the drug and would be safe for human consumption.

Acknowledgements. This work was supported in part by the US Department of Agriculture (Grant No. 85-CRSR-2-2691) and by Wallop-Breaux funds administered by the California Department of Fish and Game. The authors thank Dr Kalman Molnár, Hungarian Academy of Sciences, Budapest, Hungary, for his helpful advice, and Drs Szuts and Sárközy from the Chinoin Pharmaceutical and Chemical Works Ltd, Budapest, Hungary, for supplying the Fumagillin $\mathrm{DCH}$.

\section{LITERATURE CITED}

Alderman, D. J. (1986). Whirling disease chemotherapy. Bull. Eur. Ass. Fish Pathol. $6(2): 38-40$

Bailey, L. (1953). The effect of Fumagillin upon Nosema apis (Zander). Nature, Lond. 171: 212-213

Clifton-Hadley, R. S, Alderman, D. J. (1987). The effects of malachite green upon proliferative kidney disease. J. Fish Dis. 10: 101-107

Clifton-Hadley, R. S., Bucke, D., Richards, R. H. (1984). ProLiferative kidney disease of salmonid fish: a review. J. Fish Dis. 7: $363-377$

Foott, J. S., Hedrick, R. P. (1987). Seasonal occurrence of the infectious stage of proliferative kidney disease (PKD) and resistance of rainbow trout, Salmo gairdneri Richardson, to reinfection. J. Fish Biol. 30: 477-483

Hartwig, A., Przelecka, A. (1971). Nucleic acids in intestine of Apis mellifica infected with Nosema apis and treated with Fumagilin DCH: cytuchenicdi anả autoradiographıc studies. J. Invertebr. Pathol. 18: 331-336

Hedrick, R. P., Kent, M. L., Rosemark, R., Manzer, D. (1984). Occurrence of proliferative kidney disease (PKD) among Pacific salmon and steelhead trout. Bull. Eur Ass. Fish Pathol. 4 (3): 34-37

Hedrick, R. P., Kent, M. L., Toth, R. J, Morrison, J. K. (1988). Fish infected with Sphaerospora spp. Thelohan (Myxosporea) from waters enzootic for proliferative kidney disease of salmonid fish. J. Protozool. 35 (1): 13-18

Humason, G. L. (1979). Animal tissue techniques. W. H. Freeman Co., San Francisco

Jaronski, S. T. (1972). Cytochemical evidence for RNA synthesis inhibition by Fumagillin. J. Antibiotics 25 (6): $327-331$

Kano, T., Okauchi, T., Fukui, H. (1982). Studies on Pleistophora infection in eel, Anguilla japonica-II. Preliminary tests for application of Fumagillin. Fish Path. 17 (2): 107-114

Katznelson, H., Jamieson, C. A. (1952). Control of Nosema disease of honey bees with Fumagillin. Science 115: 70-71

Kent, M. L., Hedrick, R. P. (1985). Transmission of the causative agent of proliferative kidney disease (PKD) with the blood and spleen of infected fish; further evidence that the PKX parasite belongs with the phylum myxozoa. Bull. Eur. Ass. Fish Pathol. 5 (2): $39-42$

Kent, M. L., Hedrick, R. P. (1986). Development of the PKX myxosporean in rainbow trout Salmo gairdneri. Dis. aquat. Org. 1: 169-182

Killough, J. H., Magill, G. B., Smith, R. C. (1952). The treatment of amebiasis with Fumagillin. Science 115: 71-72

Liu, T. P. (1973). Effects of Fumidil B on the spore of Nosema apis and on lipids of the host cell as revealed by freezeetching. J. Invertebr. Pathol. 22: 364-368

Lynch, R. E., Lewis, L. C. (1971). Reoccurrence of the microsporidian Perezia pyraustae in the European corn borer, Ostrinia nubilalis, reared on diet containing Fumidil B. J. Invertebr. Pathol. 17: 234-236

Meyer, F. P., Jorgensen, T A. (1983). Teratological and other effects of malachite green on development of rainbow trout and rabbits. Tans. Am. Fish. Soc. 112: 818-824

Molnár, K. Baska, F. Szekely, C. (1987). Fumagillin, an efficacious drug against renal sphaerosporosis of the common carp Cyprinus carpio. Dis. aquat. Org. 2: 187-190

Shadduck, J. A. (1980). Effect of Fumagillin on in vitro multiplication of Encephalitizoon cuniculi. J. Protozool. 27 (2) $202-208$ 